\title{
A CLINICOEPIDEMIOLOGICAL STUDY OF MELASMA IN A TROPICAL AREA
}

\author{
B. T. V. N. Raju1, G. Ajay Kumar', K. R. Harsha Vardhan ${ }^{3}$
}

${ }^{1}$ Assistant Professor, Department of DVL, King George Hospital.

${ }^{2}$ Assistant Professor, Department of DVL, King George Hospital.

3 Postgraduate, Department of DVL, King George Hospital.

\section{ABSTRACT}

\section{BACKGROUND}

Melasma is an acquired, circumscribed, pigmentary disorder characterised by more or less symmetrically distributed, mediumto-dark brown macules with defined geographic borders affecting the sun exposed areas particularly the forehead, cheeks, temples and upper lip. Melasma is a commonly encountered pigmentary disorder in dermatological practice. The pathogenesis of melasma is unknown.

\section{AIMS}

Our present study was aimed to elucidate the epidemiology, aetiological factors and its clinical patterns in the causation of melasma in patients attended to King George Hospital (KGH) affiliated to Andhra Medical College, Visakhapatnam, Andhra Pradesh, South India.

\section{MATERIALS AND METHODS}

A total of fifty patients with melasma attended to the outpatient department of KGH were enrolled for the study. The demographic data was recorded and clinical evaluation was done. All melasma cases encountered were included and facial hypermelanoses other than melasma were excluded.

\section{RESULTS}

In this study, it was observed that patients belonging to the 31-40 years' age group were affected more (52\%) commonly (Table 1). Females (92\%) were affected more when compared to males (8\%) (Table 2). The duration of melasma more than one year was in $56 \%$ of patients (Table 3 ) and aggravation with significant sunlight exposure was noted in $70 \%$ of patients (Table 4). When compared to all other occupations, housewives (66\%) were more commonly affected (Table 5). Among the various clinical patterns of melasma, Centrofacial with malar pattern (Fig. 3) was observed in high (76\%) number of patients (Table 6). Under Wood's light examination, Epidermal type (Fig. 5) of melasma was seen in 76\% of patients and Dermal type (Fig. 6) in 24\% of patients (Table 7).

\section{CONCLUSION}

In this part (Visakhapatnam) of the country, Melasma is very common in females and mostly aggravated by Sunlight exposure during their daily normal activities.

\section{KEYWORDS}

Melasma, Sunlight, Wood's Light, Centrofacial, Malar, South India.

HOW TO CITE THIS ARTICLE: Raju BTVN, Kumar GA, Vardhan KRH. A clinicoepidemiological study of melasma in a tropical area. J. Evolution Med. Dent. Sci. 2016;5(79):5894-5897, DOI: 10.14260/jemds/2016/1330

\section{BACKGROUND}

The word melasma originates from the Greek word melas (muh-LAZ-muh) or dark is quite common in India and a major portion of patients attend to the Dermatology Clinics for the treatment of this condition. It is an acquired increase in pigmentation of the skin characterised by symmetrical and confluent grey-brown patches mostly on the areas of the face exposed to the sun such as the cheeks, nose, forehead and chin. The exact prevalence of melasma is unknown in most of the countries. Melasma is the most common pigment disorder among Indians. The disease affects all races, but it is prominent

Financial or Other, Competing Interest: None.

Submission 25-08-2016, Peer Review 20-09-2016,

Acceptance 26-09-2016, Published 03-10-2016.

Corresponding Author:

Dr. B. T. V. N. Raju,

Assistant Professor,

Department of DVL

King George Hospital, Vizag-530002.

E-mail: rajubtvn@yahoo.com

DOI: $10.14260 / \mathrm{jemds} / 2016 / 1330$ among Hispanics and Asians. It is observed more frequently among individuals with darker skin types (Type IV-VI). Melasma is more common in women of child bearing age and also seen in men. It is rarely reported before puberty. The aetiological factors are many, but none of them can be blamed as the sole factor leading to its development. The factors implicated are genetic influences, exposure to UV radiation, pregnancy, oral contraception and thyroid dysfunction. The hyperpigmentation maybe a consequence of hyperactive/hyperfunctional melanocytes that cause excessive melanin deposition in the epidermis and dermis. The number of hyperpigmented patches may range from single lesion to multiple patches located usually symmetrically on the face. The lesions have serrated, irregular and geographic borders. According to the distribution of lesions, three clinical patterns (1-Centrofacial, 2-Malar and 3-Mandibular) of melasma were recognised. By using Wood's light examination melasma can be classified into four types (1-Epidermal, 2Dermal, 3-Mixed and 4-Indeterminate). This study was aimed at studying the epidemiology, clinical presentation and aggravating factors associated with melasma. 


\section{MATERIALS AND METHODS}

This was a prospective study, carried out to know clinicoepidemiological presentation of melasma. Fifty cases of melasma of various age groups and of either sex attended to the outpatient department of Dermatology in KGH affiliated to Andhra Medical College, Visakhapatnam, were included. Facial hypermelanoses other than melasma were excluded. The demographic data regarding age, sex, duration of melasma, family history were noted. The data regarding aggravating factors such as pregnancy, sunlight exposure, use of oral contraceptives, menstrual irregularities, menopause and history of thyroid disease were recorded. Clinical evaluation was done and depending upon the distribution of lesions, they were classified under centrofacial, malar and mandibular patterns. Based on Wood's light examination, melasma was classified as epidermal and dermal types. A complete general and dermatological examination was done.

Statistical Analysis: Was done by using ratios and percentages.

\section{RESULTS}

The study comprised of fifty patients of clinically diagnosed melasma: It was observed that patients in the age group 31-40 years were affected more (52\%) commonly when compared with other age groups with $28 \%$ of patients in the 20-30 yrs. group and $20 \%$ of patients in the $41 \mathrm{yrs}$. and above group (Table 1). Females were involved commonly accounting to $92 \%$ of the total with only $8 \%$ involvement of males (Table 2). Of the total number of patients $56 \%$ were having melasma over a long duration (more than one year), whereas $44 \%$ of patients presented early (Table 3). Sunlight exposure was found to be the most common aggravating factor in $70 \%$ of patients; there was a positive family history in $16 \%$ of melasma patients and history of thyroid disease in $4 \%$ of patients. Included among the miscellaneous factors in females were OC pills $(1.38 \%)$, pregnancy $(0.46 \%)$, menstrual irregularities (2.3\%) and menopause (2.76\%) (Table 4). While considering the occupation of these patients, housewives $(66 \%)$ were found to be affected more commonly when compared to daily wage workers $(24 \%)$ and others (10\%) (Table 5). Among the clinical patterns, it was observed that the Centrofacial with malar pattern (Fig. 3) was observed in more $(76 \%)$ number of patients when compared with other patterns (Malar-14\% [Fig. 2], Centrofacial-6\% [Fig. 1], all patterns-4\% [Fig. 4]) (Table 6). Under Wood's light examination, Epidermal type (Fig. 5) was seen in $76 \%$ of patients when compared with Dermal type (Fig. 6) in $24 \%$ of patients (Table 7).

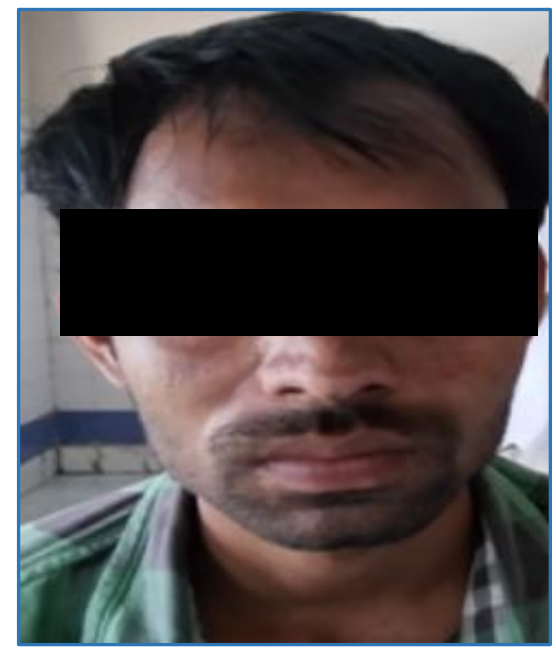

Fig. 1: Centrofacial Pattern

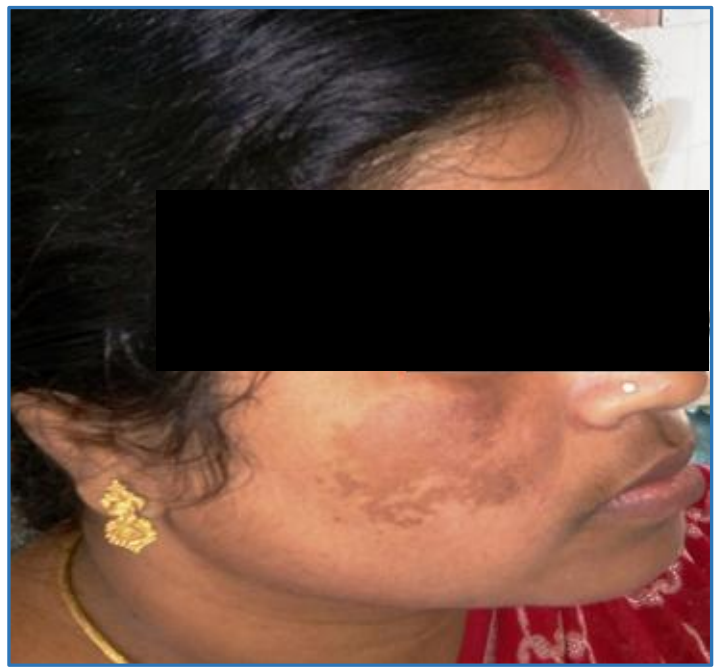

Fig. 2: Malar Pattern

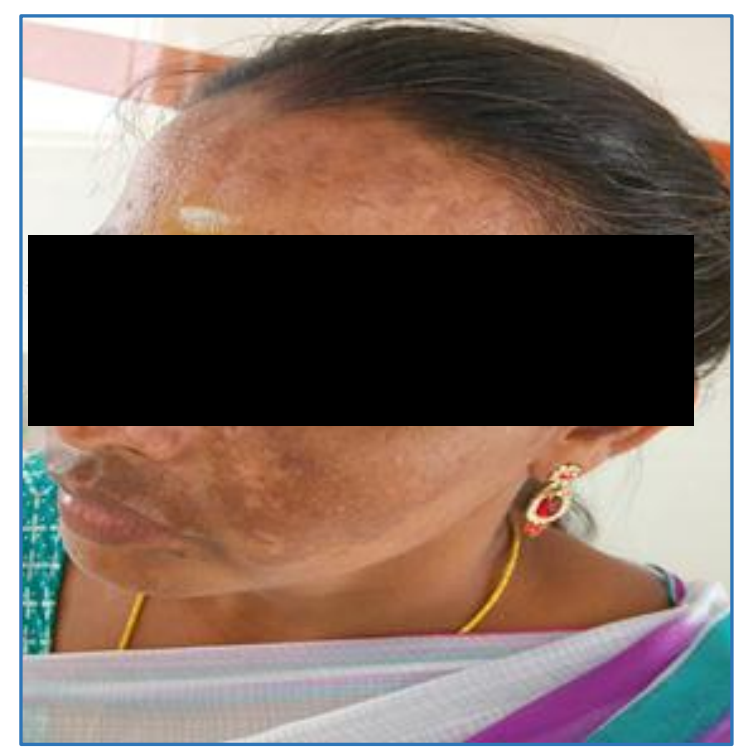

Fig. 3: Centrofacial with Malar Pattern

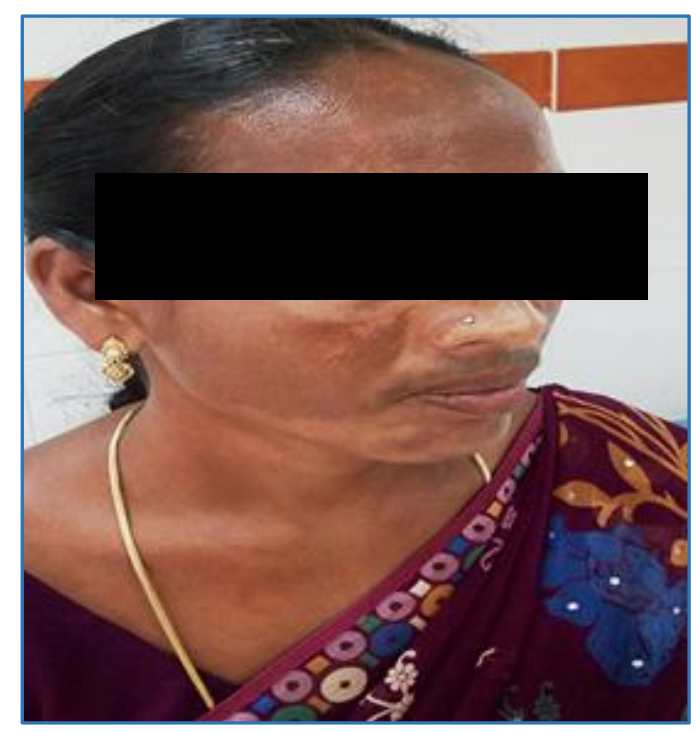

Fig. 4: Centrofacial with Malar and Mandibular Pattern 


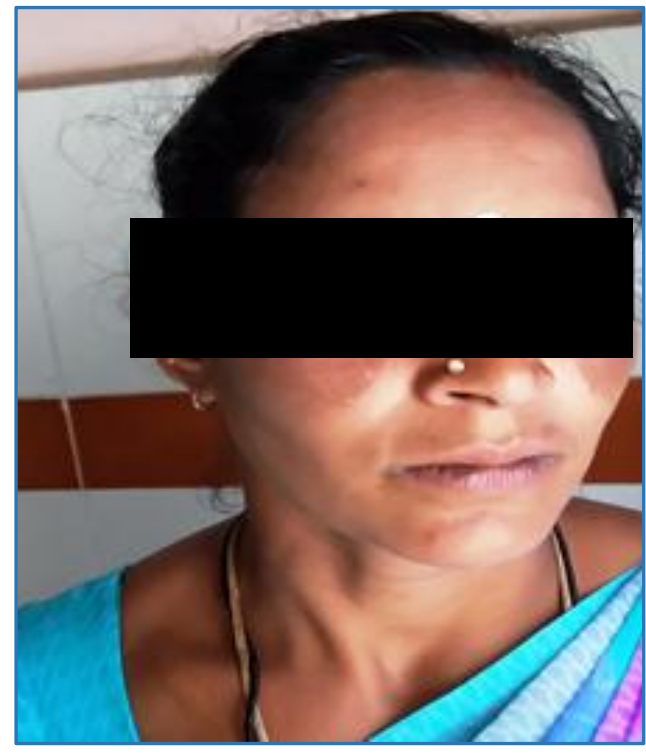

Fig. 5: Epidermal Type under Wood's Light Examination

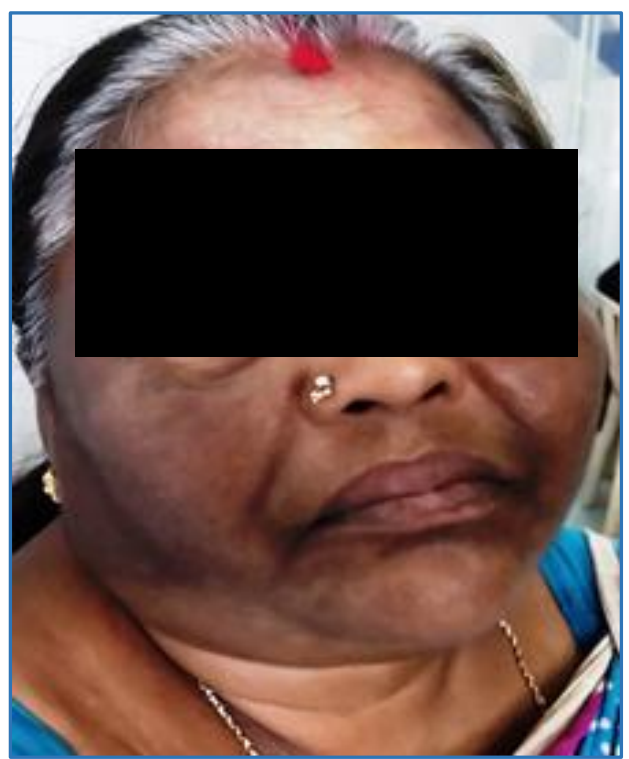

Fig. 6: Dermal Type under Wood's Light Examination

\begin{tabular}{|c|c|c|c|}
\hline $\begin{array}{c}\text { Sl. } \\
\text { No. }\end{array}$ & $\begin{array}{c}\text { Age } \\
\text { Group }\end{array}$ & $\begin{array}{c}\text { Number of } \\
\text { Patients }\end{array}$ & $\begin{array}{c}\text { Percentage } \\
\text { (\%) }\end{array}$ \\
\hline 1 & $20-30$ yrs. & 14 & $28 \%$ \\
\hline 2 & $31-40$ yrs. & 26 & $52 \%$ \\
\hline 3 & 41 yrs. and Above & 10 & $20 \%$ \\
\hline \multicolumn{3}{|c|}{ Table 1: Age Distribution } \\
\hline
\end{tabular}

\begin{tabular}{|c|c|c|c|}
\hline Sl. No. & Sex & Number of Patients & Percentage (\%) \\
\hline 1 & Male & 4 & $8 \%$ \\
\hline 2 & Female & 46 & $92 \%$ \\
\hline \multicolumn{3}{|c|}{ Table 2: Sex Distribution } \\
\hline
\end{tabular}

\begin{tabular}{|c|c|c|c|}
\hline Sl. No. & Duration & Number of Patients & Percentage (\%) \\
\hline 1 & Below 1 yr. & 22 & $44 \%$ \\
\hline 2 & Above 1 yr. & 28 & $56 \%$ \\
\hline \multicolumn{3}{|c|}{ Table 3: Duration of Melasma } \\
\hline
\end{tabular}

\begin{tabular}{|c|c|c|c|}
\hline $\begin{array}{c}\text { Sl. } \\
\text { No. }\end{array}$ & Factor & $\begin{array}{c}\text { No. of } \\
\text { Patients }\end{array}$ & (\%) \\
\hline 1 & Sun Light Exposure & 35 & $70 \%$ \\
\hline 2 & OC Pills (In Females) & 3 & $1.38 \%$ \\
\hline 3 & Pregnancy (In Females) & 1 & $0.46 \%$ \\
\hline 4 & $\begin{array}{c}\text { Menstrual Irregularities } \\
\text { (In Females) }\end{array}$ & 5 & $2.3 \%$ \\
\hline 5 & Thyroid Disease & 2 & $4 \%$ \\
\hline 6 & Positive Family History & 8 & $16 \%$ \\
\hline 7 & $\begin{array}{c}\text { Attained Menopause } \\
\text { (In Females) }\end{array}$ & 6 & $2.76 \%$ \\
\hline \multicolumn{3}{|c|}{ Table 4: Aggravating Factors } \\
\hline
\end{tabular}

\begin{tabular}{|c|c|c|c|}
\hline $\begin{array}{c}\text { Sl. } \\
\text { No. }\end{array}$ & Occupation & $\begin{array}{c}\text { Number of } \\
\text { Patients }\end{array}$ & (\%) \\
\hline 1 & Housewives & 33 & $66 \%$ \\
\hline 2 & Labour & 12 & $24 \%$ \\
\hline 3 & Others & 5 & $10 \%$ \\
\hline \multicolumn{3}{|c|}{ Table 5: Occupational Distribution of Melasma } \\
\hline
\end{tabular}

\begin{tabular}{|c|c|c|c|}
\hline $\begin{array}{c}\text { Sl. } \\
\text { No. }\end{array}$ & Pattern & $\begin{array}{c}\text { Number of } \\
\text { Patients }\end{array}$ & Percentage (\%) \\
\hline 1 & Centrofacial & 3 & $6 \%$ \\
\hline 2 & Malar & 7 & $14 \%$ \\
\hline 3 & Centrofacial+Malar & 38 & $76 \%$ \\
\hline 4 & Mandibular & 0 & $0 \%$ \\
\hline 5 & All & 2 & $4 \%$ \\
\hline \multicolumn{2}{|c|}{ Table 6: Based on Distribution of Melasma Patterns } \\
\hline
\end{tabular}

\begin{tabular}{|c|c|c|c|}
\hline $\begin{array}{c}\text { Sl. } \\
\text { No. }\end{array}$ & Type & $\begin{array}{c}\text { Number of } \\
\text { Patients }\end{array}$ & Percentage (\%) \\
\hline 1 & Epidermal & 38 & $76 \%$ \\
\hline 2 & Dermal & 12 & $24 \%$ \\
\hline \multicolumn{4}{|r|}{ Table 7: Based on Wood's Light } \\
Examination of Melasma Types
\end{tabular}

\section{DISCUSSION}

Nowadays Melasma is one of the most common causes of cosmetic concern in females. The pathogenesis is unknown but genetic, hormonal and UV radiation are important predisposing factors. In the present study, fifty cases of melasma were enrolled to evaluate the clinical features and epidemiological data. Melasma is a common dyschromia that often motivates the search for dermatological care. In the present study common age group commonly affected was 3140 years and followed by $20-30$ years' group, which correlates the study conducted by S. Kumar et al.(1) Females-to-male ratio was 11.5:1 and this ratio varied with other studies (Kavya et al study).(2) Patients with history of melasma of more than one year duration were about $56 \%$ similar to $S$. Kumar et al study.(1) Regarding aggravating factors sunlight exposure was seen in $70 \%$ of patients in the present study, which is similar to the study conducted by Krishnendra Verma et al.(3) Even though they were housewives, frequent exposure to sunlight during their daily activities they were affected as per our observation. Other aetiological factors were seen in very limited number of patients (Pregnancy, OC pills, family history, hypothyroidism and menopause). Occupationally, housewives were affected more $(66 \%)$ in number when compared with other occupations and similar findings were observed in the 
study of Vidyadhar R Sardesai et al.(4) On considering the clinical distribution, centrofacial with malar pattern (76\%) was observed in higher number of cases when compared with other patterns, the results were deferred with other studies (S. Pawar et al study and Chandravathi et al study).(5,6) Under Wood's light examination, $76 \%$ of patients have Epidermal type of melasma, the results were comparable with S. Pawar et al study and deferred with Yalda and Naser et al study.(5,7)

\section{CONCLUSION}

This study gives us an understanding of the present state of melasma in and around Visakhapatnam. Melasma was most commonly seen in middle-aged females following sunlight exposure. Clinically centrofacial with malar pattern was most common and epidermal type was found to be the commonest type under Wood's light examination.

It is important to the patients to limit sunlight exposure to the least possible extent to minimise the incidence of melasma.

\section{REFERENCES}

1. Kumar S, Mahajan BB, Kamra N. Melasma in north Indians: a Clinical, epidemiological, and etiological study. Pigment Int 2014;1:95-9.
2. Kavya M. Melasma: a clinico-epidemiological study. International J Basic and Applied Medical Sciences 2014;4(2):388-91.

3. Verma K, Kumre K, Sharma H, et al. A study of various etiological factors in the causation of melasma. Indian J Clinical and Experimental Dermatology 2015;1(1):28-32

4. Sardesai VR, Kolte JN, Srinivas BN. Melasma: a clinical study and comparison of the therapeutic effect of topical modalities for it's treatment. Indian J Dermatology 2013;58(3):239.

5. Pawar S, Khatu S, Gokhale N. Clinico-epidemiological study of melasma in Pune patients. J Pigmentary Disorders 2015;2:219.

6. Chandravathi PL, Soujanya D, Karani H. Clinicoepidemiological and biochemical profile of patients with melasma. Journal of Evolution of Medical and Dental Sciences 2015;4(81):14115-23.

7. Nahidi Y, Naser TM. A study of evaluation of clinicoepidemiological features of melasma and level of involvement on wood's lamp examination. Iranian J Dermatology 2013;16(64):57-63. 